\title{
ASPECTE DIN ISTORIA STUDIULUI COMUNICĂRII HISTORY OF COMMUNICATION STUDY
}

\author{
Silvia Nastasiu, PhD student, university lecturer, „Nicolae Testemitanu” \\ State Medical and Pharmaceutical University, Republic of Moldova \\ DOI: https://doi.org/10.31435/rsglobal_ws/30082018/6075
}

\section{ARTICLE INFO}

Received: 07 July 2018

Accepted: 21 August 2018

Published: 30 August 2018

\section{KEYWORDS}

communication,

study,

history,

epoch,

speech,

analogous,

language,

writing,

communication theories.

\begin{abstract}
This paper is a research on the history of communication study, which began and continues to develop as a field of interference in social and human disciplines. The term of communication has long been used. Studies on this domain are relatively modern, and all of them were related with controversy and syncope of semantic and paradigmatic origin. We would like to draw the attention, from many perspectives, on the progress and diversity of the theoretical approaches related to the communication process. These criteria have, over time, influenced the quality and impact of studies on this phenomenon, as well as its prolificacy in many research fields, with relevant praxiological reverberations.
\end{abstract}

Citation: Silvia Nastasiu. (2018) Aspecte Din Istoria Studiului Comunicării History of Communication Study World Science. 8(36), Vol.3. doi: 10.31435/rsglobal_ws/30082018/6075

Copyright: (C) 2018 Silvia Nastasiu. This is an open-access article distributed under the terms of the Creative Commons Attribution License (CC BY). The use, distribution or reproduction in other forums is permitted, provided the original author(s) or licensor are credited and that the original publication in this journal is cited, in accordance with accepted academic practice. No use, distribution or reproduction is permitted which does not comply with these terms.

Studiul comunicării a început și continuă să se dezvolte ca un domeniu de interferență a disciplinelor socio-umane. Noțiunea de comunicare este întrebuințată de mult timp, studiile despre acest domeniu sunt relativ moderne și nu a fost unul fără controverse și sincope de ordin semantic și paradigmatic. În viziunea specialiștilor, „debutul anevoios al studiului comunicării nu este întâmplător; mai mult, el fixează o realitate: comunicarea este o disciplină de intersecţie. În zilele noastre, orice disciplină socială este, într-o anumită măsură, o disciplină de intersecţie; comunicarea este prin excelenţă aşa ceva. Ea nu poate trăi decât absorbind şi utilizând rezultate, dezlegări, uneori câmpuri problematice din disciplinele învecinate” (Dobrescu,et.al.,2014, p.8).

Din punct de vedere etimologic, termenul comunicare ( $<$ fr. communiquer) are la bază verbul latin communico, communicare, în limba română moștenit sub forma a cumineca, având sensul „de a primi sau a da cuminecătura; a (se) împărtăși, a (se) griji” (accepție creștină). Se presupune că verbul latin communico, communicare s-ar forma de la adjectivul minus, e „care își face datoria, îndatoritor, serviabil”, care stă la baza unei nobile familii lexicale: immunis, e „scutit de sarcini”, actualmente „de contractarea unei maladii”; communis, e „comun”; dar și excommunico, excommunicare „interdicție de a primi împărtăş̧ania" etc. (Dinu, 2014, p. 24).

În antichitate, se atestă primele referiri și judecăţi despre comunicare, care vizau știința gândirii corecte şi fundamentarea discursului. La grecii antici arta vorbirii în public (elocința) era considerată una din cele mai complexe activități, se considera regina tuturor artelor și se situa pe aceeași treaptă cu muzica, arhitectura, sculptura. $\mathrm{Cu}$ ajutorul măiestriei vorbirii vii se soluționau problemele de ordin social cu participarea activă a publicului. Liderii erau cei care prin calităţi oratorice deosebite reuşeau să influenţeze rațiunea și sentimentele celor adunați în piețe prin comentarea unor aspecte de o importanță deosebită în formarea conștiinței civice. În perioada ce a 
urmat după încheierea războaielor greco-persane, cunosc o înflorire deosebită asemenea științe ca astronomia, matematica, filosofia, dialectica, etica, gramatica, cât și arhitectura, sculptura și teatrul, care stă la temelia artei oratorice ca gen de activitate. Fiind centrul dezvoltării multilaterale a personalității, Atena și-a spus cuvântul și în dezvoltarea retoricii. Retorii, persoane care își instruiau discipolii în arta cuvântului oral, erau buni cunoscători ai logicii și maieștri ai argumentării. O simplă trecere în revistă a accepțiilor comunicării la gânditorii străvechi adaugă plusvaloare importanței cruciale a actului de vorbire, în general și a celui de relaționare, în particular.

Protagoras din Abdera - în lucrările sale teoretice subliniază, în primul rând, cunoașterea limbii, necesitatea cunoașterii gramaticii ca factor primordial al comunicării publice. În opinia sa, elocința înnobilează sufletele.

Socrate (469-399 î.e.n.), un redutabil maiestru al dialogului academic, a fost primul care a recurs la ironie în comunicările sale, care servea la dezvoltarea gândirii și la transformarea discuției într-o luptă de opinii.

Adevărate drame filosofice pot fi considerate dialogurile lui Platon (427-347 î.e.n.), fiind caracterizate prin agerimea gândirii și simțul elevat al limbii. Conținutul logic, limba metaforică și expresivă a lui Platon au contribuit la dezvolatarea artei vorbirii în public. Este considerat primul filosof care a conjugat arta dialogului public cu problemele de ordin etic, cerându-i oratorului să nu se complacă în rostirea cuvintelor goale. Platon afirma că, ,așa cum medicul contribuie prin intervenția sa la schimbarea spre mai bine a stării sănătății fizice a pacientului, la fel și oratorul, prin măiestria vorbirii lui, contribuie la modelarea sufletului uman” (apud Dorogan, 1995, p. 64)

Un alt reprezentant de vază al elocinţei este Aristotel - un profesor de stil academic, care a dezvoltat gândirea teoretică în general și a filosofiei, în special. Aspectele teoretice de elocință își găsesc mai întâi reflectare în Organonul, iar mai târziu în Retorica - o primă fundamentare teoretică a acestei discipline, unde sunt tratate profund astfel de chestiuni ca limba, stilul, structura discursului. Printre exigențele sale față de limba oratorului se numărau: claritatea, frumuseţea, eleganța, accesibilitatea. În ceea ce priveşte stilul - acesta trebuie să coincidă cu subiectul discursului, să fie emoționant și inspirat pentru a cuceri ascultătorii.

Şi în Roma Antică elocința era un factor social incontestabil, unde era comparată cu strategia și tactica militară, care în principiu erau considerate ca artă în deplina semnificație a acestui cuvânt.

Perioadele Evului Mediu și Renașterii au dezvoltat idei, judecăți, considerații extrem de importante pentru comunicare, în pofida faptului că termenul propriu-zis nu era menționat. Așadar, comunicarea, chiar de la primele meditații teoretice, în Antichitate, solicită noțiuni ca realitate și cunoaștere.

Studierea și analiza comunicării, în general, este în vizorul cercetătorilor, începând cu anii ' 50 ai secolului XX. W. Schramm (1953/1996) face prima tentativă de ordonare a contribuțiilor istorice la analiza comunicării. R. E. Park, reprezentantul școlii de la Chicago a formulat, primul, multe noțiunicheie din domeniul cercetării media. În lucrarea sa The Immigrant Press and Its Control, inițiază cercetări, investigații aplicate asupra publicațiilor cu acest profil.

Totuși, menționam faptul că școala de la Chicago - prima contribuție americană consistentă și coerentă în domeniul comunicării - s-a format sub influență europeană, dat fiind faptul că doi reprezentanți importanți ai acesteia, G. H. Mead și R. E. Park, și-au făcut studiile în Germania, fiind inspirați de operele lui Wilhelm Wundt și Georg Simmel. Alți doi reprezentanți ai generației de aur ai comunicării americane, cea din anii 1940 și 1950, Kurt Lewin şi Paul Lazarsfeld sunt europeni (Schramm, 1996, p. 121). Sociologia germană și cea franceză au influențat sociologia americană și, implicit, studiul comunicării inițiat de școala americană. „Este vorba despre o influență directă exercitată prin cercetătorii americani care au venit să studieze în Germania (Park, Cooley, Lasswell etc.) sau prin cercetători europeni emigrați în SUA (Lazarsfeld, Lewis), dar și de una indirectă, dar profundă, care a avut loc prin intermediul creației diverșilor autori europeni, de la Simmel la Tönnies, de la Tarde la Wundt, de la Marx la Freud. Ideile lor au dominat formarea autorilor americani. La începuturile dezvoltării sociologiei pe noul continent, unii cercetători americani și-au propus să transpună în universitățile americane, deci într-un context schimbat, idei și abordări europene" (Dobrescu, 2007, p. 231).

Istoria comunicării ca disciplină separată are la bază mai multe studii, consemnate de Dobrescu: , istorii biografice - E. Katz et al. (2003), E. Rogers și S. Chaffee (1997), E. Rogers (1994) - sau istorii intelectuale - J. D. Peters și P. Simonson (2004), D. McQuail (2002), J. D. Peters (1999), D. Schiller (1996), H. Hardt (1992), D. Ross (1991) ( Dobrescu, 2007, p.2).

„Istoria biografică” scrisă de Everett Rogers este considerată în literatura de specialitate „,istoria standard“" a studiului comunicării, manifestând caracterul său transdisciplinar. Personalități din domenii variate (filosofie, sociologie, psihologie, științei politice etc.) - Max Weber, Georg Simmel, 
Gabriel Tarde, John Dewey sau William James etc. au analizat actul comunicării, au exprimat comentarii, explicații și au emis ipoteze, au inițiat cercetări.

Cercetătorul Schramm menționează debutul anevoios al studiului comunicării, dat fiind faptul că „este o disciplină de intersecție”, iar unele niveluri ale comunicării (comunicarea interpersonală, comunicarea de grup) implică așa discipline ca psihologia și sociologia. Caracterul de disciplină de intersecție este accentuat și de faptul că studiul comunicării nu și-a construit încă o identitate bine conturată, cum este cazul celorlalte specializări socio-umane. Statutul de disciplină de sinteză, situată la confluența altor științe socio-umane, este generos, dar pândit de foarte multe pericole (Schramm, 1996, p. 16). Statutul de interdisciplină a comunicării impune și pericolul de a se dispersa în mulțimea de domenii specializate, care conțin din belșug preocupări și direcții proprii.

Sunt semnificative în acest context opiniile cercetătorilor Haberma (The Theory of Communicative Action, 1997) și George Trey (Solidarity and Difference: the Politics of Enlightenment in the Aftermathof Modernity, 1998). Primul menționează condițiile de bună funcționare teoretică a demersului specializat, regula abordării raționale. Lucien Sfez remarca contribuția lui Habermas prin definirea comunicării: «(...) comunicarea este în social, în limba care este socială, în implicit, în prejudecată. Comunicarea nu este mecanică, ci comprehensive» (Sfez, 2002, p. 20). George Trey sesizează că teoria acțiunii comunicative reprezintă alternativa lui Habermas la politicile Iluminismului și vorbește despre,,aspirațiile normative ale acestei teorii“, ,în cele mai abstracte forme“. Cercetătorul lansează ideea că acțiunea comunicativă nu este o problemă strict de comunicare, iar procesul său de elaborare cuprinde două componente: ,pe de o parte, o reelaborare a teoriei sociale şi în special a procesului de raționalizare, pornind de la acțiunea comunicativă; pe de altă parte,o reelaborare în ceea ce privește înțelegerea comunicării însășì" (Trey, 1998, p. 9). Din acest punct de vedere, Habermas realizează o joncțiune semnificativă între structurile interne ale interacțiunii și cele ale limbajului.

Melvin L. DeFleur și Sandra Ball-Rokeach în lucrarea Teorii ale comunicării de masă cu privire la evoluția comunicării umane delimitează șase etape, numite de autori si „epoci”:

1. Epoca semnelor și semnalelor, care aparţine fiinţelor primitive, incapabile de vorbire. Acum aproximativ 2 milioane de ani: focul, topoarele cioplite din piatră, limbajul corpului, semne făcute cu brațele si mâinile erau folosite de strămoșii noștri ca semne sau semnale. Aceste mesaje erau foarte simple si transmise intr-un ritm lent.

2. Epoca vorbirii si a limbajului. Această nouă epocă este plasată în timp acum circa 40.000 de mii de ani, când oamenii de Cro-Magnon aveau structura craniană, limba și laringele ca și la oamenii contemporani. Limba i-a ajutat să-și organizeze gândirea, să producă și să transmită mesaje din ce în ce mai complexe. Se consideră că oamenii de Neanderthal au dispărut deoarece au putut trece bariera epocii semnelor și semnalelor.

3. Epoca scrisului. Istoria scrisului a evoluat de la pictogramele convenţionalizate la sisteme fonetice, de la reflectarea ideilor prin imagini sau desene, la utilizarea scrierii fonetice - a literelor.

4. Epoca tiparului: presa şi educația. Înainte de apariţia tiparului, cărţile erau scrise de mână şi erau considerate adevărate opere de artă. Chinezilor tehnica tipăriturii le era cunoscută încă din sec. al V-lea î.Chr. Prima carte din lume a fost tipărită de chinezi în anul 868 ante Chr.

În Europa, această invenție îi revine lui Johann Gutenberg din Mainz, care, în anul 1456 a terminat tipărirea Bibliei latine care avea câte 42 de rânduri pe fiecare pagină. Astfel, arta tiparului s-a răspândit vertiginos în Germania şi în întreaga Europă. Inventarea tiparului a reprezentat o adevărată revoluție în comunicare, făcând posibilă răspândirea mai rapidă a informaţiei, ceea ce a înlesnit progresul gândirii umane şi a cunoaşterii, modificând evoluția umanității.

5. Epoca mijloacelor comunicării de masă. Sec. al XIII-lea este influențat și de descoperirile spiritului renascentist, unde își ia avânt dezvoltarea informației universale și susținerea permanentă a interesului crescut al oamenilor pentru cunoaștere. Astfel, presa periodică apare la începutul sec. al XVII-lea prin două împrejurări: perfecționarea tiparului și organizarea poștei ca serviciu permanent și regulat. Odată cu începutul sec. al XIX-lea, presa periodică a fost însoțită de telegraf și telefon, iar la începutul sec. al XX-lea, - de radiou și televiziune. Mijloacele comunicării de masa au accelerat ritmul vieții umane, de astfel si comunicarea. Presa de masa, cinematograful, radioul si televiziunea au produs mutații culturale, sociale, politice si economice.

6. Epoca mijloacelor de comunicare computerizat, epoca computerelor care au format o „societate a informațiilor". Odată cu apariția internetului, a calculatoarelor personale și a rețelor de telecomunicații sofisticate, comunicarea devine o problemă majoră într-o societate dependentă de informații ( DeFleur, Ball-Rokeach, 1999, pp.21 - 38).

Potrivit lui McLuhan, istoria consemnează trei mari epoci istorice de comunicare: 
a) epoca oralității - conversația ca mijloc propriu-zis de comunicare; antrenează persoana și toate simțurile sale deodată, auzul însă rămâne simțul dominant;

b) epoca culturii scrise - instalează văzul ca simț dominant și introduce o disociere între văz și celelalte simțuri, care devin secundare; inventarea scrierii fonetice, adică transformarea sunetelor, fără nicio semnificație, în simboluri vizuale, de asemenea lipsite de semnificație; inventarea tiparului; textul scris sau tipărit;

c) epoca apariției electricității și a tehnologiilor - apare telegraful, telefonul, televizorul și computerul; are loc reorchestrarea simțurilor, asemănătoare ca în epoca oralității.

În viziunea autorului McLuhan, evoluția comunicării este marcată de două revoluții tehnologice majore:

a) cea a inventării tiparului, înfăptuită la jumătatea secolului al XV-lea;

b) cea a electricității, realizată către sfârșitul veacului al XIX-lea.

Aceste revoluții recurg la simțuri diferite, deoarece utilizează alte tehnologii și toate acestea transformă felul nostru de a gândi și de a percepe lucrurile, de care, de cele mai multe ori, nu suntem conștienți. „Oamenii se schimbă“, menționează McLuhan, „când se schimbă raporturile dintre simțuri. Iar acestea se schimbă când vreunul dintre simțuri sau vreo funcție corporală sau mintală este exteriorizată sub formă tehnologică“. Pentru McLuhan, „tehnologia este o extensie a ființei umane, formulă care exteriorizează întreaga teorie a simțurillor. Fiecare mijloc de comunicare apelează cu predilecție la unul dintre simțuri și favorizează o ierarhie a importanței acestora în procesul comunicării. Conversația, ca prim mijloc de comunicare, dominantă în epoca oralității, apelează la toate simțurile ființei umane: auz, văz, simțul tactil, olfactiv”. În culturile orale, simțurile „,colaborează“, „interacționează“, dar sub „tirania covârşitoare a urechii“"(după Dobrescu, et al. 2007, p. 3).

Așadar, concluzionăm asupra vechimii și diversității abordărilor teoretice a procesului de comunicare din varii perspective, care, de-a lungul timpului, au influențat benefic calitatea și impactul studiilor fenomenului dat, dar și prolificitatea acestuia în numeroase domenii de cercetare, cu reverberații praxiologice relevante.

În studiul comunicării, în general, menționăm două mari teorii:

1. Semiologia comunicării, dezvoltată de semioticienii Eric Buyssens, Jeanne Martinet, Louis Prieto (Baylon,et.al.,1991,p. 51), care își fundamentează teoria pe distincția dintre semnal și indiciu, primul presupunând intenționalitatea;

2. Scoala de la Palo Alto, care elaborează renumitele ,axiome” ale comunicării. Paul Watzlawick, Janet Beavin, Don Jackson (Watzlawick, et.al., 1972, p. 45-47) menționează faptul că orice comportament are o valoare comunicativă, iar indici semnal / indiciu sunt irelevanți, dat fiind faptul că „,noncomunicarea este imposibilă”.

Cercetătorul Ion-Ovidiu Pânișoară subliniază, că „,comunicarea capătă un bogat istoric într-o varietate de teorii ale fenomenelor sociale de ansamblu", evidențiind tratarea inter-/, pluri/transdisciplinară drept condiție în stabilirea științei comunicării: „comunicarea devine o megaștiință care, departe de a extrage corpusul teoretic și metodologic din științele care au studiat-o în mod implicit, le va oferi acestora (...) instrumente avansate de cercetare (...)" (Pânișoară, 2015, p. 25). Prezentăm în continuare acest istoric elucidat în teoriile comunicării:

1. Teoria cibernetică. Norbert Wiener, considerat părintele ciberneticii, intenționează să dezvolte o științ̆ă generală a comunicării, aplicabilă omului și mașinii și pune accent pe feedback (procedee de control ce permit unui sistem să fie ajustat la context) și organizare socială: „,...) sistemul social este un tot organizat, ca și individul; că este unit de un sistem de comunicații; că are o dinamică în care procesele circulare de feedback joacă un rol important" (Weiner, 1966, p. 50, apud Pânișoară, 2015, p.27).

2. Teoria matematică asupra comunicării, denumită și teorie a inginerilor, dat fiind faptul că autorii Claude Elwood Shannon și Warren Weaver sunt ingineri; în obiectiv - identificarea mijloacelor sigure și rapide de transportare a informațiilor, problema transmiterii eficiente a unei cantități maxime de informații. Shannon consideră comunicarea drept „reproducerea într-un punct dat (...) a unui mesaj selecționat într-un alt punct” (apud Mattelart, Mattelart ,2001, p.44).

Teoria respectivă distingea 3 niveluri ale problemelor:

a) Nivel tehnic al problemelor - transmisiunea simbolurilor comunicării.

b) Nivel semantic al problemelor - corelația simbolurilor transmise și înțelesuri.

c) Nivel de eficiență ale problemelor - atingerea rezultatului scontat.

3. Școala de la Palo Alto sau „colegiul invizibil”. Reprezentanții acestui colegiu (P.Watzlawick, J.H.Beavin, D.Jackson) evidențiază că orice tip de comportament uman are valoare comunicativă. Se face o diferențiere între conținutul mesajului și relația de comunicare (= maniera). 
4. Teoriile structurale implică, în esența lor, școala lingvistică, dezvoltată de Ferdinand de Suassure; limba este o Instituție socială (un sistem organizat de semne care exprimă idei), iar vorbirea este individuală. Despre știința comunicării lingvistul considera că „,se poate concepe o știință care studiază viața semnelor în sânul vieții sociale (...) o vom numi semiologie. Ea ne învață în ce constau semnele şi ce legi le conduc" (apud Mattelart, Mattelart,2001, p. 66).

5. Structuralismul. Comunicarea este concepută ca totalitatea regulilor care preexistă individului și sunt preluate de către acesta. Exponentul acestui curent, Claud Levi-Starus, introduce noțiunile de obiectivitate/ subiectivitate, experiență comunicațională etc.

Roman Jakobson (1929) delimitează funcțiile limbajului: funcția expresivă, funcția conotativă, funcția poetică, funcția referențială, funcția fatică și funcția metalingvistică .

6. Sociologiile interpretative (anii 60 ai secolului trecut). Dintre multele teorii cuprinse aici, vom mentiona:

a) Interacționalismul simbolic sau Școala de la Chicago. Herbert Blumer, fondatorul acestui concept, delimitează trei premise principale (1969) în actul comunicării: ,„prima premisă este aceea că oamenii acționează faţă de lucruri pe baza semnificațiilor pe care le au pentru ei aceste lucruri. A doua este că semnificația acestor lucruri derivă sau se naște din interacțiunea socială a unui individ cu alți actori. A treia este că aceste semnificații sunt utilizate și modificate într-un proces de interpretare efectuat de individ în raportul său cu lucrurile pe care le întâlnește" (Mattelart, Mattelart 2001, p. 105; Lohisse, 2002, p. 152).

Erving Goffman evidențiază importanța normelor de natură organizațională, negocierea, teritorialitatea: ,am menționat două tipuri de locuri în care pacienții au un control neobișnuit: locurile libere şi teritoriile de grup. Ei le împart pe primele cu orice alt pacient, și pe celelalte, doar cu câteva persoane (selectate în acest sens)" (Goffman, 1991, p. 216, apud Pânișoară, 2015, p.32) etc.

b) Etnometodologia. Teoria pornește de la studiul simțului comun într-o schemă a activității, iar ,studiile etnometodologoce urmăresc analizarea activităților de fiecare zi ca metode folosite de membrii grupului, cu scopul de a face aceste activități vizibil raționale şi raportabile pentru toate scopurile pratice (...)"(Garfinkel, 1992, p.vii, apud Pânișoară, 2015, p.33).

7. Etnografia comunicării. Exponenții acestei teorii (C. Bachmann, J. Lindenfeld J. Simonin) consideră comunicarea interpersonală drept un fenomen cultural și propun modelul „speaking”, constituit din 8 elemente: „,cadrul fizic și psihologic; participanți (toți cei prezenți); finalități (obiective și rezultate); acte (conținutul și forma mesajului); tonalitate (desfășurarea activității de limbă); instrumente (mijloace de comunicare); norme (de interacțiune și de interpretare); gen (tip de activitate de limbaj)" (apud Lohisse, 2002).

8. Abordări ale teoriilor comunicării din perspectiva studiilor comunicării organizaționale cuprinde descrierea modelului în care diferite abordări comunicative au fost preluate în calitate de teorii ale comunicării în studiul organizațiilor (dimensiune organizațională). Pot fi identificate perspectivele: normativă, interpretativă, critică, dialogică.

Așadar, teoriile comunicării abundă în perspective de abordare și interpretare și contează pentru noi aspectul relațional calitativ, de impact, asupra partenerilor, dar și substanța/mesajul transmis și receptat, care dă sens activității umane la general și a celei profesionale, în special.

\section{REFERENCES}

1. Dobrescu, Paul; Bârgăoanu, Alina ;Nicoleta Dobrescu. (2007),Istoria comunicări, București: Comunicare.ro, $376 \mathrm{p}$.

2. Dorogan, M., (1995), Curs de elocință, Chișinău, Ed. Arc,

3. DeFleur, M. L., Ball-Rokeach, S., (1998), Teorii ale comunicarii de masa, Editura: Polirom, 280 p.

4. Lesenciuc, Adrian. (2017), Teorii ale comunicării /. - Ed. a 2-a, reviz. - Braşov: Editura Academiei Forţelor Aeriene "Henri Coandă", 316 p.

5. Lohisse J. (2002), Comunicarea. De la transmiterea mecanică la interacțiune. Iași,: Editura Polirom

6. Mattelart A., Mattelart B. (2001), Istoria teoriilor comunicării. Iași: Editura Polirom

7. Pânișoară, I.O. (2015) Comunicare eficientă, ediția a 4-a, Iași: Polirom,478 p.

8. Saussure, F. (2003), Scrieri de lingvistică generală; text stabilit și editat de Simon Bouquet și Rudolf Engler, cu colab. lui Antoinette Weil; trad. de Luminița Botoșineanu Iași: Polirom, 352 p.

9. Schramm, Wilbur (1953/1996), „There Were Giants on the Earth These Days“, in EveretteE. Dennis, Ellen Wartella (eds.), American Communication Research. The Remembered History, Lawrence Erlbaum Associates, Mahwah, New Jersey.

10. Sfez, Lucien. (2002). O critică a comunicării. Traducere de Radu Gârmacea, Raluca Popescu și Sorin Gherguț. Bucureşti: comunicare.ro

11. Trey, George (1998), Solidarity and Difference: the Politics of Enlightenment in the Aftermathof Modernity, State University of New York Press, New York 